\title{
O Uso das TIC nas Práticas dos Professores de Matemática da Rede Básica de Ensino: o projeto Mapeamento e seus desdobramentos
}

\section{The Use of ICT in Practice of Mathematics Teachers of Basic Education: the project Mapping and its consequences}

\author{
Sueli Liberatti Javaroni* \\ Maria Teresa Zampieri**
}

\begin{abstract}
Resumo
Esse artigo tem o propósito de apresentar o projeto Mapeamento do uso das tecnologias de informação nas aulas de Matemática do Estado de São Paulo, bem como os resultados oriundos do mosaico de pesquisas que constituem esse projeto. Além disso, apresentamos e discutimos uma ação de formação continuada que ocorreu no período de agosto a novembro de 2014 na cidade de Bauru, que se refere a um curso de extensão universitária. Para tanto, dialogamos com uma literatura dentro da Educação Matemática, que aponta que o uso das TIC pode potencializar os processos de ensino e aprendizagem, porém há empecilhos que dificultam esse uso nas escolas. Em seguida, trazemos os resultados iniciais do projeto, frutos de pesquisas que o compõem, as quais seguem uma abordagem metodológica qualitativa. Diante disso, posicionamos esse curso de extensão universitária, que por sua vez, teve o objetivo de fomentar o uso das TIC nas práticas de professores de Matemática da Educação Básica. Finalmente, argumentamos que o desenvolvimento de projetos dessa natureza possibilita um trabalho colaborativo de pesquisa, que tem por consequência o incentivo da articulação entre pósgraduação, licenciaturas e escolas da rede pública de Educação Básica.
\end{abstract}

Palavras-Chave: GeoGebra. Formação do Professor. Curso de Extensão Universitária. Observatório da Educação (OBEDUC). Colaboração.

\begin{abstract}
This article aims to present the project Mapping the use of information technology in Mathematics classes of the State of São Paulo, as well as the results of the "mosaic of research" that constitute this project. In addition, we present and discuss an action of continuing education that occurred in the period from August to November 2014 in the city of Bauru, which refers to a university extension course. To this end, we dialogue with literature within

\footnotetext{
* Doutora em Educação Matemática pela Universidade Estadual Paulista "Júlio de Mesquita Filho" (UNESP), Cidade/SP. Professora do Departamento de Matemática, Faculdade de Ciências da Universidade Estadual Paulista (UNESP), Bauru/SP. Endereço para correspondência: Av. Luiz Edmundo Carrijo Coube, 14-01, Vargem Limpa, Bauru/SP, CEP 17033-360. E-mail: suelilj@fc.unesp.br.

** Mestre em Educação Matemática pela Universidade Estadual Paulista "Júlio de Mesquita Filho" (UNESP), Rio Claro/SP. Doutoranda, Instituto de Geociências e Ciências Exatas da Universidade Estadual Paulista "Júlio de Mesquita Filho" (UNESP), Rio Claro/SP. Endereço para correspondência: Rua Antonio C. G. M. Lacerda, 97, Nova Piracicaba, Piracicaba/São Paulo, CEP: 13.405-171. E-mail: maite.zampieri@gmail.com. Bolsista FAPESP, processo \#2014.27166-9.
} 
the Mathematics Education, which points out that the use of ICT can enhance teaching and learning processes, but there are obstacles that hinder this use in schools. Then, we bring the initial results of the project, fruit of research that make it up, which follows a qualitative methodological approach. Therefore, we position this course of university extension, which in turn, aimed to promote the use of ICT in the practices of mathematics teachers of Basic Education. Finally, we argue that the development of such projects enables collaborative research, which has the effect of encouraging the articulation between graduate and undergraduate students and Basic Education public schools.

Keywords: GeoGebra. Teacher Training. Course of University Extension. Observatório da Educação (OBEDUC). Collaboration.

\section{Introdução}

Há mais de três décadas, a Educação Matemática vem se consolidando internacionalmente enquanto área de pesquisa. Segundo Bicudo (1993), a Educação Matemática se preocupa com o fazer Matemática, com o compreender a Matemática, com interpretações sobre significados culturais, históricos e sociais da Matemática, bem como as ações político-pedagógicas em seu entorno. "São, portanto, pesquisas que solicitam domínio compreensivo de um vasto horizonte de conhecimentos, como os horizontes da Psicologia, da História, da Filosofia...” (BICUDO, 1993, p. 20).

Dentro do âmbito das pesquisas científicas, vem se tornando cada vez mais frequente o desenvolvimento de projetos de pesquisa temáticos, dos quais podem fazer parte projetos de pesquisa de mestrado, de doutorado, de iniciação científica, etc. Essa prática já vem se tornando frequente também na Educação Matemática. No grupo de pesquisa em que somos membros, o GPIMEM" ${ }^{1}$, utilizamos o termo "mosaico de pesquisas" (BORBA, 2004) para caracterizarmos a forma como se entrelaçam as pesquisas que compõem um determinado projeto temático. Fazemos isso com o intuito de "discutir a noção de que um conjunto de investigações com focos particulares distintos, mas sobre o mesmo tema, permite uma análise longitudinal sobre a área, o que permite, por sua vez, que se tenha uma compreensão mais abrangente da mesma" (ZAMPIERI; CHINELLATO; CHIARI, 2013).

Assim se configura o projeto de pesquisa temático Mapeamento do uso das tecnologias de informação nas aulas de Matemática do Estado de São Paulo ${ }^{2}$, aprovado sob n 16429 no Edital 049/2012/CAPES/OBEDUC/INEP e coordenado pela primeira autora desse trabalho. Esse projeto iniciou-se em março de 2013 e encontra-se em fase de desenvolvimento. Seu objetivo geral é identificar como as tecnologias da informação e

\footnotetext{
${ }^{1}$ Grupo de Pesquisa em Informática, Outras Mídias e Educação Matemática. http://igce.rc.unesp.br/\#!/gpimem. Último acesso em 27.04.2015.

${ }^{2}$ Para melhor fluidez do texto, nos referiremos ao projeto apenas como Mapeamento.
} 
comunicação (TIC) vêm sendo utilizadas nas aulas de Matemática do Ensino Fundamental Anos Finais ( $6^{\circ}$ ao $9^{\circ}$ ano do Ensino Fundamental) na Educação Básica do Estado de São Paulo. Como objetivo específico, o Mapeamento tem desenvolvido ações de formação continuada com professores de Matemática da Educação Básica, buscando articular o uso das TIC com os conteúdos que compõem o currículo oficial paulista, da disciplina de Matemática, em particular do EF - Anos Finais.

Buscando atingir o objetivo geral do projeto, foram escolhidas seis Diretorias Regionais de Ensino do estado de São Paulo, que estão localizadas nos municípios de Bauru, Guaratinguetá, Limeira, Presidente Prudente, Registro e São José do Rio Preto. A escolha de tais diretorias de ensino se deu visando dois principais motivos. Um deles, porque as cidades contempladas estão localizadas em diferentes regiões do estado de São Paulo. Um segundo e tão importante fato é que nessas cidades ou próximas às elas, como por exemplo a cidade de Limeira, temos campus da Unesp, o que nos proporciona suporte técnico e recurso humano para o desenvolvimento de possíveis ações de colaboração para fins do cumprimento dos objetivos proposto no projeto.

Faz-se necessário esclarecer ainda que, desde a ocasião da implementação do projeto Mapeamento, o Programa Acessa Escola ${ }^{3}$, implementado através da Resolução $037^{4}$ de 25/4/2008 (inserir fonte), é o programa oficial estadual paulista que disciplina o uso dos laboratórios de informática das escolas estaduais paulistas da Educação Básica. Assim, os projetos de iniciação científica, de mestrado e doutorado, ligados ao Mapeamento, tomaram como ponto de partida para suas investigações as escolas públicas paulistas das diretorias de ensino abrangidas que atuam com os anos do EF - Anos Finais e que têm o Programa Acessa Escola ativado.

São então colaboradores desse projeto alguns docentes da Unesp, dos campi de Bauru, Guaratinguetá, Presidente Prudente, Rio Claro e São José do Rio Preto, bem como alguns discentes que estão sob a orientação deles, em projetos de pesquisa de iniciação científica, mestrado e doutorado. Oito professores de Matemática da Educação Básica, vinculados às diretorias de ensino abrangidas pelo Mapeamento, também fazem parte da equipe de colaboradores. Destacamos ainda que, desde o início de sua implementação, temos desenvolvido reuniões a distância, utilizando-se da sala virtual do adobe connect ${ }^{5}$, bem como realizamos reuniões presenciais com subgrupos dos colaboradores, conforme a demanda das

\footnotetext{
${ }^{3}$ http://acessaescola.fde.sp.gov.br/Public/Index.aspx. Último acesso em 20.04.2015.

${ }^{4} \mathrm{http}$ ://acessaescola.fde.sp.gov.br/Admin/Handlers/ArquivoComp.ashx?jkasdkasdk=122\&type=Alterar. Último acesso em 20.04.2015.

${ }^{5}$ http://www.adobe.com/br/products/adobeconnect.html . Último acesso em 15/04/2015.
} 
atividades. Nessas reuniões, definimos as funções de cada colaborador dentro do projeto e, de forma coletiva, refletimos e organizamos ações mais gerais e às vezes mais específicas, conforme explicitaremos mais adiante.

Diante do exposto, nesse artigo temos o propósito de discorrer acerca do projeto Mapeamento, bem como de resultados oriundos do "mosaico de pesquisas" que constituem esse projeto. Além disso, apresentamos e discutimos uma ação de formação continuada que ocorreu no período de agosto a novembro de 2014 na Diretoria de Ensino de Bauru, que se refere a um curso de extensão universitária intitulado "Currículo no Ensino Fundamental II e atividades matemáticas com softwares: articulações possíveis”. Esse curso compõe o cenário de pesquisa de doutoramento da segunda autora desse artigo.

\section{$2 \mathrm{O}$ uso das TIC e o professor de Matemática}

Estamos vivendo em uma sociedade onde o uso das TIC se faz presente dentro de distintas atividades cotidianas. Entretanto, ao lançarmos nosso olhar para o contexto educacional, em particular para as aulas de Matemática, a presença das TIC nem sempre acontece. Não se trata de estabelecer uma relação dicotômica entre usar e não usar as TIC, mas sim de considerar inexorável esse uso dentro da sociedade contemporânea. Nesse sentido, concordamos com Kenski (1999, p. 46) quando afirma que a "sociedade digital" não é caracterizada pela oposição ou exclusão aos modelos tecnológicos anteriores, ou seja, "sua característica é a ampliação de possibilidades e o envolvimento".

$\mathrm{Na}$ tentativa de acompanhar esse movimento no contexto educacional, muitos programas governamentais, tanto em âmbito federal quanto estadual, foram criados com o intuito de equipar os laboratórios de informática das escolas, bem como preparar os professores para utilizá-los em suas práticas pedagógicas. Alguns exemplos são: “Educação e computadores (Educom), o Projeto Nacional de Formação de Recursos Humanos em Informática na Educação (Formar) e o Programa Nacional de Informática na Educação (Proinfe)" (CHINELlATO, 2014, p. 26). No contexto do Estado de São Paulo, especificamente, outros programas foram criados também com esses mesmos propósitos, dentre eles o "A Escola de cara nova na era da informática", de 1998, e em 2008, o programa “Acessa Escola", o qual está vigente no momento, cujos esclarecimentos já mencionamos anteriormente. 
Diante dessas colocações, reforçamos a necessidade de que os professores de Matemática tenham a oportunidade de conhecer e de se apropriar do uso das TIC dentro de suas práticas. Em consonância com Ponte (2014, p. 354)

\begin{abstract}
Perceber quais as potencialidades das tecnologias que podem ser mobilizadas para contextos formativos e identificar modos de as usar de forma produtiva na formação inicial e contínua, tanto com os professores que já usam com muita destreza estas tecnologias, como com professores que mantêm com elas uma relação incipiente, constituem aspetos importantes de uma agenda atual de investigação nesse campo.
\end{abstract}

As investigações que se propõem a debater as potencialidades das TIC nos processos de ensino e aprendizagem de Matemática e sobre a importância de que tal debate seja fomentado tanto na formação inicial quanto na continuada do professor, vem se expandindo no Brasil. Borba e Penteado (2010) discutem acerca das dificuldades que alguns professores têm de sair de sua zona de conforto. O termo zona de conforto, segundo eles, pode ser concebido como sendo as ações e os comportamentos que o professor está acostumado a realizar em sua prática didática, por diversos anos em sua profissão, e que não lhe causa insegurança ou risco. Esses autores pontuam a dificuldade que alguns professores têm em avançar para uma zona de risco, onde "é preciso avaliar constantemente as consequências das ações propostas" em suas práticas de sala de aula e "[...] procuram caminhar numa zona de conforto onde quase tudo é conhecido, previsível e controlável”. E por vezes, mesmo insatisfeitos, "[...] eles não se movimentam em direção a um território desconhecido" (BORBA; PENTEADO, 2010, p. 56), preferindo permanecer em sua zona de conforto. Porém, ainda, segundo esses autores,

[...] ao caminhar em direção à zona de risco, o professor pode usufruir o potencial que a tecnologia informática tem a oferecer para aperfeiçoar sua prática profissional. Aspectos como incerteza e imprevisibilidade, geradas num ambiente informatizado, podem ser vistos como possibilidades para [...] desenvolvimento do aluno, desenvolvimento do professor, desenvolvimento das situações de ensino e aprendizagem (BORBA; PENTEADO, 2010, p. 66).

Os autores argumentam que são vários elementos que podem levar o professor a lidar com zonas dessa natureza, sendo que o uso das TIC nas salas de aulas pode ser uma delas. Tais riscos são associados, em particular, à perda de controle da classe, que podem surgir decorrentes das dúvidas que emergem dos alunos quando estes estão trabalhando com o computador. Eles argumentam que, mesmo que "o professor seja experiente é sempre possível que uma nova combinação de apertar de teclas e comando leve a uma situação nova que, por vezes, requer um tempo mais longo para análise e compreensão" (BORBA; PENTEADO, 2010, p. 57). Outro fator que pode ser associado à zona de risco consiste na eventualidade de problemas técnicos com o computador que podem surgir, os quais os professores não têm a 
obrigação de dominar. Temos ainda a questão da necessidade de constante atualização acerca de novos softwares, que surgem continuamente.

Apesar dessas possíveis dificuldades, os autores ressaltam a importância de que o professor enfrente suas zonas de risco para promover mudanças em suas práticas, em particular o professor de Matemática. Em contrapartida, eles pontuam que esse não é o caminho mais fácil a ser tomado, e sim, talvez, o mais árduo. Nesse sentido, eles argumentam que o professor avança pouco para essa zona, saindo de seu conforto, se ele não reflete acerca disso com outras pessoas, sejam professores e/ou pesquisadores. Diante disso, "é necessário encontrar formas de oferecer um suporte constante para o trabalho do professor" (BORBA; PENTEADO, 2010, p. 67).

Miskulin (2003) discorre acerca de um possível redimensionamento na formação colaborativa de professores de Matemática com o propósito de fomentar reflexões críticas a respeito de métodos e estratégias de ensino que contemplem os avanços tecnológicos. Para que isso seja possível, ela argumenta sobre uma nova dimensão no processo de formação de professores, a qual "concebe o "aprender fazendo", ou seja, que concebe a ação educativa como um processo de construção, no qual os sujeitos, futuros professores [no caso da formação inicial], serão aprendizes e construtores de sua própria formação" (MISKULIN, 2003. p. 5, grifo do autor).

Nesse mesmo sentido, Rosa, Pazuch e Vanini (2012, p. 99) denominam de Cyberformação uma concepção de formação de professores voltada para o uso das TIC nos processos de ensino e aprendizagem da Matemática. Desse modo, eles têm o propósito de que os professores pensem com as TIC “de forma a refletirem/discutirem situações problema relativas aos conceitos matemáticos em questão, a fim de transformar/potencializar os processos de formação continuada". Dentro dessa perspectiva, os autores pontuam que os professores são convidados a analisar as potencialidades de materiais (atividades ou recursos feitos com as TIC) para a produção de conhecimento matemático, e ainda se busca que eles desenvolvam seus próprios materiais em sintonia com o processo reflexivo de pensar com as TIC.

Já Gama e Fiorentini (2009, p. 447) analisaram o processo de formação continuada dentro de alguns grupos colaborativos, compostos por professores de Educação Básica, professores universitários, pós-graduandos e coordenadores de escola. Nesse estudo, os autores perceberam "a disponibilidade e a abertura para receber diferentes membros que se interessam pela formação e pela qualidade do processo de ensino e aprendizagem de matemática". Uma das características desses grupos, destacadas por eles, é a voluntariedade, 
ou seja, só participam aqueles que de fato têm interesse nas temáticas abordadas dentro de tais grupos. No entanto, os autores enfatizam que a colaboração entre todos os participantes não acontece de imediato, demandando tempo e confiança para que eles respeitem os objetivos pessoais de cada um, bem como os objetivos do grupo como um todo. Outro fato que despertou a atenção dos autores foi a forma como os participantes lidaram com eventuais conflitos e divergência de opiniões. Para eles, as interações entre os participantes, mesmo quando não chegam a um consenso comum, podem propiciar a produção de conhecimento. Argumentam ainda que, mesmo com "a divisão histórica entre acadêmicos e práticos, que trabalham em culturas e/ou comunidades de prática distintas e respondam a exigências diferentes, nas últimas décadas tem-se buscado, nas parcerias colaborativas, os aprendizados mútuos e a superação dessa distinção" (GAMA; FIORENTINI, p. 450).

Em sintonia com tais ideias, Souto (2013, p. 26) reflete sobre o sentimento dos professores quando se deparam com a "necessidade de mudança provocada pela inserção das TIC em suas respectivas práticas docentes”. Ela argumenta que esse tipo de sentimento, por um lado, pode acarretar em imobilidade, mas por outro, pode provocar mudanças, se os professores se sentirem instigados. A autora argumenta que dentro da diversidade de olhares de educadores matemáticos sobre as perspectivas em formação continuada de professores, há o reconhecimento de "uma nova forma de trabalho [nessa área] que se caracteriza por ações colaborativas, o que exige minimamente, uma mudança de postura, que coloca a individualidade em um segundo plano" (SOUTO, 2013, p. 26).

Ponte (2014) considera que tanto a formação inicial quanto a continuada devem ser alicerçadas em termos de mudança na cultura profissional. Ou seja, ao invés de assumirem uma cultura de adaptação dentro do que lhes é imposto dentro da escola, "os professores devem ser encorajados a trocar experiências com outros colegas e a envolver-se na realização de projetos coletivos, na participação e na transformação das condições do ensinoaprendizagem" (PONTE, 2014, p. 353). Mas, se pensarmos no contexto brasileiro, mais especificamente no Estado de São Paulo, foco das nossas pesquisas vinculadas ao projeto Mapeamento, os professores estão sendo encorajados a se engajar nessa transformação no que se refere a usar as TIC em suas aulas?

As considerações trazidas por Borba e Penteado (2010) a esse respeito se embasam em um contexto investigado há mais de uma década atrás, uma vez que, a primeira edição dessa obra é do ano de 2001. Para eles, "se o professor não tiver espaço para refletir sobre as mudanças que acarretam a presença da informática [...], eles tenderão a não utilizar essas mídias, ou a utilizá-las de maneira superficial” (BORBA; PENTEADO, 2010, p. 88-89). 
Diante disso, eles argumentam que, para lidar com as incertezas trazidas por essas mudanças, é necessário um amplo trabalho de reflexão coletiva.

Mas e atualmente, há na escola ou em outros contextos de formação esse espaço para reflexão coletiva acerca do uso das TIC nas aulas de Matemática? A escola apoia o professor a lidar com essas mudanças? Possui uma infraestrutura que viabiliza e incentiva a utilização das salas de informática? Essas e outras questões são discutidas em resultados de trabalhos dentro do "mosaico de pesquisas" do projeto Mapeamento, os quais pontuaremos a seguir.

\section{Resultados do "mosaico de pesquisas" do projeto Mapeamento}

As pesquisas de mestrado, doutorado e iniciação científica vinculadas ao projeto Mapeamento seguem uma abordagem metodológica qualitativa. Em tal abordagem "há sempre uma interrogação posta (ou pergunta ou problema), há rigor e sistematicidade na condução da busca e, o mais importante, há um fio condutor tecido pelo raciocínio articulador do autor" (BICUDO, 1993, p. 21). Assim, cada uma das pesquisas discorre acerca de uma pergunta diretriz, fruto da inquietação do respectivo pesquisador, abordando de um jeito particular o uso das TIC nas aulas de Matemática no Estado de São Paulo, contexto onde o projeto Mapeamento está inserido. O que as diferencia é o fio condutor tecido dentro de cada pesquisa, pois mesmo com um tema convergente, os aportes teóricos e os cenários de pesquisa são distintos, bem como o raciocínio articulador de cada pesquisador colaborador, que carrega em si sua própria subjetividade.

Por exemplo, Silva, Medeiros e Morelatti (2014) investigaram a região de Presidente Prudente. O foco da pesquisa deles foi avaliar as condições físicas dos laboratórios de informática das escolas estaduais paulistas daquela região. Eles evidenciaram que há falta de manutenção, na maior parte dos laboratórios visitados naquela ocasião, e ressaltam a necessidade de que sejam disponibilizados mais recursos para o ensino, como internet mais rápida, lousas digitais e projetores, etc. Eles concluem argumentando que "é preciso um trabalho eficaz e mais colaboração de técnicos para assistências, buscando o melhor aproveitamento dos laboratórios de informática para o ensino" (SILVA et al., 2014). Por outro lado, eles evidenciaram também casos onde há escolas com laboratórios bem equipados, porém os professores não os utilizam com seus alunos.

Paulo e Firme (2014), assumindo uma postura fenomenológica, investigaram as condições dos laboratórios de informática das escolas vinculadas à Diretoria de Ensino de Guaratinguetá, com o propósito de compreender como os computadores estavam sendo 
utilizados por alunos e por professores de Matemática. As pesquisadoras argumentam que, embora o Programa Acessa Escola tenha o propósito de propiciar a inclusão digital, e promover o fortalecimento de uma rede de professores, "a falta de manutenção nos laboratórios e de preparo de recursos humanos tem feito com que poucas metas sejam atingidas" (PAULO; FIRME, 2014, p. 601). Entretanto, elas constatam que, nessa região de inquérito, o programa atende ao objetivo de inclusão digital na comunidade escolar, sem fins educativos. Ademais, as pesquisadoras apontam que a maioria dos professores entrevistados manifesta interesse em participar de cursos de formação continuada voltado para o uso das TIC.

Chinellato (2014) teve por objetivo analisar como os computadores estavam sendo utilizados nas aulas de Matemática das escolas públicas paulistas de Limeira. Além dos percalços envolvendo infraestrutura, análogos aos que foram constatados nas pesquisas citadas anteriormente, ele concluiu que tanto na formação inicial quanto na continuada dos professores que participaram de sua pesquisa, não houve uma preparação que possibilitasse a eles a apropriação da utilização dos computadores em suas práticas escolares. Além disso, o autor apresenta que, em entrevistas com professores, muitos deles afirmam possuírem receio de utilizar com seus alunos os laboratórios pelo fato de que se algo acontece nesse ambiente, como por exemplo, quebra ou sumiço de algum equipamento, eles seriam responsabilizados pelo fato. Assim, o pesquisador critica, de maneira geral, a falta de apoio por parte da direção de escolas aos professores, no sentido de incentivá-los a utilizar os laboratórios de informática. Para ele,

a direção escolar deveria apoiá-los, dando autonomia aos docentes no que diz respeito à utilização do laboratório de informática. Reforço a ideia da autonomia que precisa ser dada ao professor, para que este possa criar confiança e sentir-se respaldado em utilizar o laboratório de informática de tal forma que, se algo acontecer lá dentro (sumiço de alguma peça ou danificação de uma máquina, entre outros), ele não venha a sofrer qualquer tipo de punição ou até mesmo seja proibido de voltar a usar os equipamentos (CHINELLATO, 2014, p. 90).

Em contrapartida, o pesquisador reconhece a importância do Programa Acessa Escola, principalmente pelo fato de propiciar aos laboratórios, recursos pertinentes tanto para a investigação de conteúdos da Matemática (softwares GeoGebra ${ }^{6}$ e Graphmática ${ }^{7}$ ), quanto para ajudar o professor a controlar a dinâmica de aula (software BlueLab ${ }^{8}$ ).

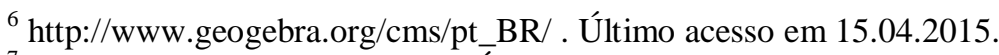

${ }^{7} \mathrm{http}: / / \mathrm{www} . \mathrm{graphmatica.com/}$. Último acesso em 27.04.2015.

8 O bluelab é um software que auxilia o professor no gerenciamento da aula no laboratório de informática, permitindo compartilhamento de arquivos, monitoramento de sites acessados pelos alunos, etc. http://www.blueonline.com.br/ . Último acesso em 15.04.2015.
} 
Andrade, Baldoni e Javaroni (2014) investigaram acerca das condições físicas e administrativas dos laboratórios de informática das escolas públicas ligadas à Diretoria de Ensino de Bauru. Em suas considerações, apontam

\begin{abstract}
a existência de poucos laboratórios, na cidade de Bauru, atendendo as metas que o Programa Acessa Escola traça, e muitos outros com dificuldades, no que diz respeito ao funcionamento da sala. (...) evidenciamos os seguintes percalços: indisponibilidade de estagiários; o número pequeno de computadores em relação ao número de alunos por turma; problema com a conexão com a rede (ANDRADE; BALDONI; JAVARONI, 2014, p. 1).
\end{abstract}

Refletindo acerca dos mesmos percalços evidenciados dentro desse contexto, Andrade, Zampieri e Javaroni (2014) argumentam sobre a necessidade de que o Programa Acessa Escola se aperfeiçoe em diferentes aspectos e que haja "um acompanhamento de tempos em tempos para averiguar quais foram os resultados para a comunidade escolar com relação ao uso dos laboratórios de informática e, principalmente, se está sendo feito o bom uso destes" (ANDRADE; ZAMPIERI; JAVARONI, 2014, p. 5761). As autoras entendem como "bom uso" dos laboratórios quando estes estão articulados a práticas pedagógicas que sejam significativas para a aprendizagem dos alunos.

Diante disso, baseadas em Borba e Penteado (2010), elas argumentam a importância de haver ações isoladas, sejam elas provenientes de universidades, empresas, etc., para atuar no mesmo sentido em que as ações governamentais na tentativa de incentivar o uso das TIC nas escolas. Assim, elas posicionam o projeto Mapeamento como uma ação isolada dentro do Estado de São Paulo, uma vez que ele "buscará articular as ações de grande escala do Acessa Escola com as particularidades de seis regiões do Estado de São Paulo, no que tange a fomentar a inserção dos computadores nas aulas de Matemática" (ANDRADE; ZAMPIERI; JAVARONI, 2014, p. 5762).

Ligada a essa mesma Diretoria de Ensino, a regional de Bauru, Oliveira (2014) desenvolveu sua pesquisa que teve por propósito investigar se as TIC estavam sendo utilizadas em salas de aulas, por professores de Matemática na cidade de Bauru. Além disso, teve o intuito de apontar as formas de uso e/ou mostrar os motivos que justificassem o não uso dos computadores nas aulas de Matemática daquela região. Discutindo seus resultados, ela aponta que os professores que usam as TIC em suas aulas, o fazem apenas para dar uma aula ou outra, de forma desvinculada ao processo de ensino, sem promover mudanças na aprendizagem de seus alunos. "Enfim, as utilizam para produzir os materiais que serão trabalhados com os alunos e os levam eventualmente uma ou duas vezes no laboratório de informática da escola" (OLIVEIRA, 2014, p. 28). A pesquisadora conclui ainda que os professores não se sentem suficientemente preparados para utilizar as TIC em suas aulas. 
Outro fator evidenciado por ela que justifica o não uso é a precariedade das condições de trabalho docente. "Desanimados por conta da desvalorização profissional, os professores têm sido sujeitos passivos na educação, o que nos faz ponderar que ainda temos muito, ou quase tudo, por fazer pelos nossos professores" (OLIVEIRA, 2014, p. 112).

Já Peralta (2014), discute acerca de seu projeto de pesquisa de mestrado, o qual tem o propósito de identificar as características dos professores de Matemática que utilizam as TIC em suas aulas. Os participantes de sua pesquisa são professores de Matemática vinculados à Diretoria de Ensino Regional de São José do Rio Preto. Vale ressaltar que a pesquisadora posiciona sua pesquisa frente aos resultados pouco satisfatórios em relação ao uso das TIC apontados, em particular por Chinellato (2014) e Oliveira (2014), os quais pouco diferem do cenário mostrado por Borba e Penteado (2010) há mais de uma década atrás. Para ela, levando em conta tais resultados, é necessário saber quem são os professores que superam as barreiras apontadas nessas pesquisas, o que "torna-se importante para um contraponto dessa situação. É necessário saber quais são as características desse professor e, uma vez feito isso, buscar sintetizar o que o leva a utilizar as Tecnologias Informáticas em suas aulas de Matemática" (PERALTA, 2014, p. 1).

Diante da exposição de tais pesquisas, podemos observar o movimento em que se encontra o projeto Mapeamento. Em um primeiro momento, as pesquisas vinculadas a ele buscaram atender o objetivo geral de identificar como as TIC estão sendo usadas nas aulas de Matemática das escolas vinculadas às Diretorias de Ensino investigadas, e de fato o fizeram. Para tal objetivo, foram avaliados os laboratórios de informática das escolas públicas paulistas que possuem o Programa Acessa Escola em funcionamento. Pelos resultados apresentados, podemos responder a última questão colocada na seção anterior em relação à infraestrutura das escolas. Constatamos que, na maior parte dos laboratórios visitados, há distintos empecilhos que inviabilizam o seu uso, tais como: número insuficiente de computadores por número de alunos, computadores inoperantes, falta de estagiário do Acessa Escola, entre outros. Também podemos responder as duas primeiras questões, uma sobre a formação dos professores para o uso das TIC, e a outra se há incentivo, por parte da escola, para que esse uso se concretize. Pelas pesquisas de Chinellato (2014) e Oliveira (2014), que tiveram seus focos voltados para os professores de Matemática, de modo geral, os professores não se sentem suficientemente seguros para utilizar as TIC em suas aulas, sendo um dos fatores a falta de preparo para isso, tanto em relação à formação inicial, quanto em relação à continuada. A falta de incentivo por parte da escola, mais especificamente por parte da direção, foi um dos fatores identificados na pesquisa de Chinellato (2014). 
Já em um segundo momento do projeto, além de avançar nessa identificação acerca dos laboratórios em regiões ainda a investigar, como por exemplo, as escolas públicas ligadas à Diretoria de Ensino de Registro, estamos promovendo ações de formação continuada, com o intuito de fomentar o uso das TIC nas aulas de Matemática dentro das regiões investigadas pelo projeto. No segundo semestre de 2014, uma delas aconteceu no município de Bauru, e no primeiro semestre de 2015, houve duas, que ocorreram nos munícipios de Limeira e Registro. A pesquisa de Peralta (2014), mesmo não promovendo uma ação específica, a nosso ver, se enquadra nesse segundo momento na medida em que abre caminho para que isso ocorra. Afirmamos isso, pois seus resultados foram levados em consideração para o planejamento de um curso de extensão vinculado a essa Diretoria, o qual está agora em fase de desenvolvimento.

Tanto no primeiro, quanto no segundo momento do projeto, consideramos relevante destacar a importância dos resultados dessas pesquisas para a Educação Matemática. Retomando o que Bicudo (1993) nos esclarece, uma das preocupações dentro dessa área de inquérito é com as ações político-pedagógicas em seu entorno. Nesse sentido, os resultados vinculados ao projeto salientaram como estão se dando as ações político-pedagógicas voltadas para o uso das TIC em seis regiões distintas dentro do Estado de São Paulo. É uma pequena área de abrangência se levarmos em conta o Brasil como um todo, mas de grande porte dentro do Estado de São Paulo. Além disso, algumas dessas pesquisas apontam perspectivas futuras. Por exemplo, diante de seus resultados, Oliveira (2014) aponta para a necessidade de desenvolvimento de propostas de formação continuada que se iniciem no contexto de atuação do professor, e que depois perpassem outros contextos, se estendendo para outros ambientes, de forma que ele tenha a possibilidade de interagir com demais professores, tanto no mesmo nível de escolaridade em que ele atua, quanto em outros níveis.

Estando parcialmente em consonância com essa perspectiva futura apontada por Oliveira (2014), na pesquisa de doutorado da segunda autora desse artigo, colocou-se em prática uma ação de formação continuada, que, por sua vez, não se originou no contexto de atuação dos professores, mas sim em outro ambiente. Mesmo assim, eles tiveram a oportunidade de interagir com colegas, que atuam em distintos níveis de escolaridade. Essa ação aconteceu na cidade de Bauru, por meio de um curso de extensão universitária, ocorrido no período de agosto a novembro de 2014. A escolha de desenvolver a primeira ação de formação nessa região se deu porque naquela época havia um número maior de colaboradores atuando lá, a saber: duas alunas de Iniciação Científica, a professora coordenadora de núcleo pedagógico (PCNP) da área de Matemática, a professora coordenadora do Mapeamento, 
pertencente ao campus de Bauru e, principalmente, a doutoranda com suas inquietações de pesquisa, o que facilitou bastante o andamento da documentação pertinente para a aprovação do curso nas instâncias, Secretaria da Educação do Estado de São Paulo e na Unesp, e posterior divulgação nas escolas. O planejamento desse curso foi discutido entre os colaboradores deste projeto por meio de reuniões semanais virtuais ocorridas no ambiente virtual do Adobe Connect e também por meio de um grupo fechado em uma rede social. A equipe proponente dessa ação foi composta pelas duas autoras desse artigo, por duas alunas de iniciação científica da Unesp, campus de Bauru e pela professora colaboradora da Educação Básica, da Diretoria de Ensino de Bauru. A seguir, passamos a tecer considerações sobre essa ação, bem como sobre alguns resultados iniciais já evidenciados a partir da análise de um recorte dos dados produzidos na pesquisa de doutorado.

\section{0 curso de extensão universitária "Currículo no Ensino Fundamental II e atividades matemáticas com softwares: articulações possíveis"}

O curso de extensão universitária promovido na Diretoria de Ensino de Bauru teve o objetivo de "incentivar a integração das tecnologias digitais nas práticas dos professores de Matemática do Ensino Fundamental II, e também promover discussões sobre assuntos que permeiam essa integração" (ZAMPIERI, 2014, p. 1111). Ele contou com uma carga horária total de 40 horas, sendo 32 horas presenciais e 8 horas na modalidade a distância, realizadas em etapas síncronas e assíncronas no Ambiente Virtual de Aprendizagem (AVA) Moodle.

Em um primeiro momento, tínhamos pensado em dividir o curso em 3 módulos, sendo o primeiro dedicado a abordar conceitos de informática básica, como por exemplo: componentes da Microsoft Office, sistemas operacionais, visitas a sites de conteúdos matemáticos, exploração do BlueLab, etc. No segundo módulo pretendíamos abordar o manuseio do software de matemática dinâmica GeoGebra. Pretendíamos ainda instigar os professores a refletirem em grupos acerca das potencialidades e limitações de atividades matemáticas com este software, com o intuito de que eles fizessem adaptações das mesmas, para contemplar suas respectivas salas de aula. No terceiro módulo, proporíamos aos professores que levassem as atividades adaptadas a suas salas de aula e que depois relatassem aos demais participantes do curso os detalhes desse processo (ZAMPIERI, 2014).

Entretanto, desde que iniciamos o planejamento desse curso, tínhamos em mente que ele não seria fechado, ou seja, que se ajustaria de acordo com as necessidades dos professores participantes. Logo, na prática, ele seguiu uma dinâmica um pouco diferente dessa, de forma 
que o primeiro módulo foi totalmente eliminado, com exceção da abordagem ao BlueLab. Prevaleceram então as características colocadas nos módulos 2 e 3, uma vez que desde o primeiro encontro com os professores, evidenciamos uma forte expectativa por parte deles em obter um conhecimento aprofundado em relação ao GeoGebra (uma dessas atividades pode ser visualizada no Anexo). Diante disso, unimos esforços entre os colaboradores do projeto na tentativa de atender a essas expectativas. Na etapa a distância, inicialmente havíamos pensado em apenas complementar as discussões que aconteciam na etapa presencial e discutir também outras possibilidades de TIC para a sala de aula. Mas na realidade, ela acabou ocorrendo seguindo a mesma dinâmica dos encontros presenciais.

Vale ressaltar que a ação que envolveu tanto o planejamento como o desenvolvimento do curso foi marcada por uma importante palavra, a saber: colaboração. Os motivos que nos levam a dar ênfase a esse fato decorrem desde o planejamento do curso, pois conforme já anunciado anteriormente, foram realizadas reuniões semanais virtuais com os colaboradores do projeto Mapeamento, até o seu desenvolvimento junto com os professores participantes. Ao iniciarmos o planejamento do curso, realizamos um levantamento bibliográfico acerca de formação continuada de professores de Matemática. Dentre as obras analisadas, duas nos chamaram a atenção por estarem em sintonia com a nossa ideia de desenvolver um curso bastante flexível que visasse atender, acima de tudo, as demandas trazidas pelos professores, a partir das suas necessidades para atender seus alunos, em suas respectivas salas de aula.

Assim, no que tange à formação continuada de professores, considerando-a permeada pelas TIC, corroboramos Rosa, Pazuch e Vanini (2012) que a entendem como um processo que não é passível de conclusão, ou seja, a formação continuada do professor é um processo que está sempre em movimento. Essa é uma das características que os autores reforçam sobre a concepção de Cyberformação, onde esse movimento ou "essa perseguição/busca pela transformação, pela concretização do projeto pelo qual nos tornamos humanos, é justamente o formar-se como ação constante de dar forma e não como uma situação que deva ser atingida" (ROSA; PAZUCH; VANINI, 2012, p. 92).

A segunda obra que nos despertou atenção e que embasou as nossas ações foi Gama e Fiorentini (2009). Para esses autores, o conhecimento é produzido de modo coletivo. "As características desses coletivos fazem emergir a colaboração, considerando que demandam tempo e confiança para que seus integrantes se constituam como participantes colaborativos que respeitam os objetivos individuais e grupais" (GAMA; FIORENTINI, 2009, p. 449). Assim, evidenciamos nos dados de nossa ação de formação, quatro distintas dimensões de colaboração, as quais emergiram a partir das características dos coletivos formados por: 
colaboradores do projeto, equipe proponente do curso, professores e pesquisadores, e professores. A seguir abordamos cada dimensão.

Primeira dimensão: entre os colaboradores do projeto. Os colaboradores têm um objetivo em comum que é contribuir, cada um em seu respectivo subprojeto, para o desenvolvimento do projeto Mapeamento. Paralelamente a isso, cada colaborador tem um objetivo individual dentro do projeto. De modo geral, os colaboradores pesquisadores da universidade se preocupam com o desenvolvimento de suas respectivas pesquisas, os colaboradores professores da rede básica se preocupam em contribuir com as ações do projeto dentro das respectivas Diretorias de Ensino em que atuam, seja para otimizar o acesso dos colaboradores das escolas, seja para contribuir com o planejamento e desenvolvimento de ações de formação voltadas para o uso das TIC, como essa que promovemos. Assim, embora essas reuniões virtuais objetivassem atender as necessidades dos colaboradores que estavam atuando em Bauru, tanto o tema que estávamos estudando, quanto a preparação das atividades eram de interesse de todos, uma vez que outras ações estão acontecendo para atender as demais Diretorias abordadas pelo projeto e envolverão todos os colaboradores. Assim, as características desse coletivo de indivíduos permitiram com que cada um se constituísse como participante colaborativo, conforme argumentam Gama e Fiorentini (2009).

Segunda dimensão: entre a equipe proponente do curso. Como já mencionamos a equipe proponente do curso foi composta pelas duas autoras desse artigo, por duas alunas de Iniciação Científica do curso de Licenciatura em Matemática da Unesp de Bauru e pela PCNP de Matemática da Diretoria Regional de Ensino de Bauru. Paralelamente às reuniões virtuais, a equipe proponente mantinha contato quase diário, e que se intensificou ainda mais no decorrer do curso. A equipe buscava sistematizar todos os conteúdos elencados pelos professores participantes do curso, bem como ideias e sugestões que emergiam nesse ambiente, para posteriormente, pensar na elaboração de mais atividades para contemplar essas necessidades trazidas pelos professores participantes. As dúvidas que emergiam nesse processo, principalmente as que envolviam um conhecimento mais avançado dos recursos do GeoGebra eram discutidas nas reuniões virtuais.

Terceira dimensão: entre pesquisadores e professores. No primeiro encontro foi esclarecido aos professores participantes que o curso seria desenhado junto com eles, ou seja, que tomaria um rumo a partir da demanda que emergisse deles. Em um primeiro momento sentimos que eles não esperavam por isso, e sim, por algo que já estivesse pronto para ser fornecido. Contudo, depois que começamos a mostrar a eles que as suas respectivas salas de aula que conduziriam o curso (isso se iniciou a partir do momento em que pedimos a eles que 
elencassem os conteúdos que gostariam de trabalhar), observamos que, do mesmo modo que estávamos colaborando com eles, a recíproca também foi verdadeira, pois evidenciamos esforços por parte deles em provocar mudanças em suas salas de aula ao levarem suas atividades adaptadas para desenvolver com seus alunos. Embora pesquisadores e professores da Educação Básica tenham propósitos distintos entre si, conforme já pontuaram Gama e Fiorentini (2009), diante dessa terceira dimensão de colaboração que evidenciamos, defendemos que o aprendizado mútuo permitiu a superação dessa divisão histórica existente entre essas duas classes de profissionais, pelo menos dentro do contexto do curso.

Quarta dimensão: entre os professores. Os professores, durante cada encontro, realizavam as atividades em duplas ou trios. Assim, dentro de cada um desses pequenos grupos, evidenciamos empenho em desenvolver as atividades e curiosidade para explorar os recursos do software GeoGebra. Depois de cada atividade, sentávamos em volta de uma mesa para debater de forma coletiva acerca da relevância ou não de tal atividade para o contexto em que cada um estava inserido. Nesse momento os professores davam várias sugestões, seja na forma de abordagem do conteúdo trabalhado, seja em distintos recursos do GeoGebra que não estavam sendo contemplados na atividade. Do mesmo modo que muitas dessas sugestões convergiam, outras também divergiam, mas o respeito pela opinião alheia prevaleceu, caracterizando assim a participação colaborativa de cada um (GAMA; FIORENTINI, 2009). Observamos ainda que os professores assumiram um papel central dentro do curso, buscando analisar criticamente e também construir suas próprias atividades, assim como defendem Rosa, Pazuch e Vanini (2012).

Analisando essas características particulares referentes a cada dimensão, argumentamos que todo o nosso caminhar envolvido nessa ação de formação vai na direção do que Souto (2013) denomina de uma nova forma de trabalho, caracterizada por colaboração, que exige, mesmo que de forma mínima, uma mudança de postura, onde a ideia de coletividade se torna marcante. Tais dimensões também, a nosso ver, estão em sintonia com o que Miskulin (2003) preconiza como redimensionamento da formação de professores, considerando este como um processo de construção, ou seja, concebe os professores como sendo construtores de sua própria formação.

Argumentamos ainda que essa dinâmica de curso só foi possível de ser constituída por meio das discussões entre todos os colaboradores do projeto, conforme esclarecemos na primeira e na segunda dimensão. Assim, além de elaborarmos a proposta do curso com base, principalmente, em Rosa, Pazuch e Vanini (2012) e Gama e Fiorentini (2009), buscamos ainda contemplar os resultados do "mosaico de pesquisas" do projeto Mapeamento. 
Especificamente, procuramos atender as necessidades de desenvolver um curso de extensão voltado para o uso das TIC, na tentativa de transformar, mesmo que minimamente, os cenários insatisfatórios evidenciados por Chinellato (2014) e Oliveira (2014). Ainda, objetivando atender as expectativas futuras apontadas por Oliveira (2014) e o interesse dos professores por cursos de formação continuada (PAULO; FIRME, 2014), o planejamento de nossa proposta foi flexível o bastante para atender as expectativas dos professores, a partir da demanda trazida de suas respectivas salas de aula.

\section{Considerações finais}

Neste artigo apresentamos o projeto Mapeamento, bem como discorremos e analisamos ações e resultados que têm sido obtidos com seu desenvolvimento. Além disso, tecemos considerações sobre uma ação de formação continuada que faz parte desse projeto, que ocorreu no ano de 2014 na Diretoria de Ensino de Bauru, que se refere a um curso de extensão intitulado "Currículo no Ensino Fundamental II e atividades matemáticas com softwares: articulações possíveis".

Para tanto dialogamos com uma literatura a respeito de TIC e o professor de Matemática, a qual aponta que essa relação pode potencializar os processos de ensino e aprendizagem, mas por outro lado é conturbada na medida em que há distintos empecilhos que dificultam a sinergia entre ambos. Em seguida, trouxemos os resultados obtidos em subprojetos ligados ao projeto Mapeamento, os quais corroboram esses argumentos e, infelizmente até o momento, apontam para um cenário pouco satisfatório em relação ao uso das TIC nas aulas de Matemática do EF-II de escolas públicas paulistas, muito próximo ao que já fora alardeado por Borba e Penteado (2010), reedição da obra de 2001, início da década passada. Os motivos que implicam em tal cenário parecem continuar se configurando os mesmos: a não integração das TIC nos processos de ensino e aprendizagem de Matemática, fato esse muito fortemente ligado à falta de apropriação desses recursos na formação inicial e continuada de professores, pois "as mudanças educacionais que têm sido propostas, em vários níveis, podem não chegar ao avanço esperado, caso não se apropriem das novas produções do homem e das necessidades da sociedade, e, assim sendo, permanecerá a escola alheia [...]" (MISKULIN, 2003, p. 3).

Em seguida posicionamos a ação de formação continuada dentro do projeto Mapeamento, a qual envolveu tanto a fase de planejamento quanto desenvolvimento do curso. Afirmamos que a colaboração foi a característica predominante nessa ação e a evidenciamos 
dentro de quatro dimensões: entre os colaboradores do projeto, entre a equipe proponente, entre pesquisadores e professores e entre os professores.

Ressaltamos que, embora seja uma pequena ação se tomarmos o Brasil todo como parâmetro, não é ínfima se considerarmos o Estado de São Paulo. Assim, esperamos com essa ação quebrar "o paradigma em que ainda estamos inseridos, no que tange a não-integração das tecnologias digitais nas aulas de Matemática. Ou seja, buscamos propiciar uma formação que coloque em sintonia integração de tecnologias digitais, projetos pedagógicos e Programa Acessa Escola” (JAVARONI; ZAMPIERI; OLIVEIRA, 2014, p. 973).

Destacamos ainda que outras ações de formação continuada já aconteceram e ainda estão acontecendo este ano, mais especificamente nos municípios de Limeira, Registro e São José do Rio Preto, conforme já mencionamos anteriormente. Assim como no caso do curso que aqui discutimos, o planejamento foi feito por meio das reuniões virtuais no Adobe Connect de acordo com a primeira dimensão de colaboração que apresentamos anteriormente. Destacamos que cada um deles teve/está tendo seu ritmo próprio, teve/está tendo seu próprio objetivo, mas uma característica é comum a todos: a colaboração. Por meio da divulgação de nossas ações em âmbito nacional e internacional, almejamos inspirar novas ideias, mas queremos acima de tudo que essa característica seja indissociável da formação de professores, tanto inicial quanto continuada, e que transcenda esse contexto... que ela seja impregnada positivamente em toda atividade humana. Estamos sendo demasiadamente otimistas? Possivelmente. Mas esse sentimento é uma fração do fio condutor que foi tecido pelos raciocínios articuladores das autoras nesse presente artigo, então cabe a nós não o deixarmos de lado.

Finalmente, o desenvolvimento de projetos dessa natureza, em formato de guardachuva onde suas hastes são compostas pelos subprojetos de iniciação científica, de mestrado e de doutorado, com o fomento da CAPES, por meio de Editais como o do âmbito do Programa Observatório da Educação (OBEDUC), da Diretoria de Formação de Professores da Educação Básica (DEB/CAPES), possibilita uma maior aproximação entre a Universidade e Escola. Isto porque o desenvolvimento do projeto Mapeamento proporciona o envolvimento de professores pesquisadores colaboradores, orientadores de projetos de pesquisa de alunos de graduação da Unesp, em vários campi, bem como orientadores de projetos de pesquisa de mestrado e de doutorado do Programa de Pós-Graduação em Educação Matemática, da Unesp de Rio Claro, e de professores de Matemática da Educação Básica, criando assim um grupo que desenvolve um trabalho colaborativo de pesquisa, que tem por consequência o incentivo 
da articulação entre pós-graduação, licenciaturas e escolas da rede pública de Educação Básica.

\section{Agradecimento}

O presente trabalho foi realizado com apoio do Programa Observatório da Educação, Coordenação de Aperfeiçoamento de Pessoal de Nível Superior - CAPES/Brasil, entidade do Governo Brasileiro voltado para a formação de recursos humanos.

\section{Referências}

ANDRADE, P. F.; BALDONI, A. C. P.; JAVARONI, S. L. A Escola pública e o uso do computador: um olhar para a estrutura física dos laboratórios de informática das escolas da Diretoria de Ensino de Bauru. In: XXVI CONGRESSO DE INICIAÇÃO CIENTÍFICA, 26., 2014, [S.I.]. Anais...[S.1.: s.n.], 2014.

ANDRADE, P. F.; ZAMPIERI, M. T.; JAVARONI, S. L. O computador e a prática pedagógica: os laboratórios de informática das escolas estaduais públicas de Bauru. In: CONGRESSO NACIONAL DE FORMAÇÃO DE PROFESSORES, 2., 2014, Águas de Lindóia. Anais... [s.n.], 2014.

BICUDO, M. A. V. Pesquisa em Educação Matemática. Pro-Posições, Campinas, v. 4, p. 18-23, mar. 1993.

BORBA, M. C. Dimensões da Educação Matemática a Distância. In: BICUDO, M. A. V.; BORBA, M. C. Educação Matemática: pesquisa em movimento. São Paulo: Cortez, 2004.

BORBA, M. C.; PENTEADO, M. G. Informática e Educação Matemática. 4. ed. Belo Horizonte: Autêntica, 2010.

CHINELLATO, T. G. O uso do computador em escolas públicas estaduais da cidade de Limeira/SP. Inserir ano. 104 f. Dissertação (Mestrado em Educação Matemática) - Instituto de Geociências e Ciências Exatas, Universidade Estadual Paulista "Júlio de Mesquita Filho", Rio Claro, 2014.

GAMA, R. P.; FIORENTINI, D. Formação continuada em grupos colaborativos: professores de matemática iniciantes e as aprendizagens da prática profissional. Educação Matemática Pesquisa, inserir cidade, v. 11, p. 441-461, inserir mês, 2009.

JAVARONI, S. L.; ZAMPIERI, M. T.; OLIVEIRA, F. T. Tecnologias digitais: é possível integrá-las às aulas de matemática? In: III CONGRESSO INTERNACIONAL DAS TIC NA EDUCAÇÃO, inserir número do evento, 2014, Lisboa/Portugal. Anais... Lisboa/Portugal: [s.n.], 2014. Disponível em: <http://ticeduca2014.ie.ul.pt/downloads/AtasDigitais/Atas_Digitais_ticEDUCA2014.pdf〉. Acesso em: 15 abr. 2015.

KENSKI, V. M. Novas tecnologias, o redimensionamento do espaço e do tempo e os impactos no trabalho docente. Informática Educativa, v. 12, n. 1, p. 35-52, 1999.

MISKULIN, R. G. S. As possibilidades didático-pedagógicas de ambientes computacionais na formação colaborativa de professores de matemática. In: FIORENTINI, D. (Org.). Formação de professores de Matemática: explorando novos caminhos com outros olhares. Campinas: [s.n.], 2003. p. 248. 
OLIVEIRA, F. T. A inviabilidade do uso das tecnologias da informação e comunicação no contexto escolar: o que contam os professores de matemática? 2014.169 f. Dissertação (Mestrado em Educação Matemática)- Instituto de Geociências e Ciências Exatas, Universidade Estadual Paulista "Júlio de Mesquita Filho", Rio Claro, 2014.

PAULO, R. M.; FIRME, I. C. O Programa Acessa Escola: um Espaço para Atuação com as TIC. In: III CONGRESSO INTERNACIONAL DAS TIC NA EDUCAÇÃO, 3., 2014, Lisboa/Portugal. Anais... Lisboa/Portugal: [s.n.], 2014. Disponível em: <http://ticeduca2014.ie.ul.pt/downloads/AtasDigitais/Atas_Digitais_ticEDUCA2014.pdf >. Acesso em: 15 abr. 2015.

PERALTA, P. Perspectivas Teóricas sobre as Características dos Professores que Utilizam as Tecnologias Informáticas em suas Aulas de Matemática In: XVIII ENCONTRO BRASILEIRO DE ESTUDANTES DE PÓS-GRADUAÇÃO EM EDUCAÇÃO MATEMÁTICA, 18., 2014, Recife. Anais... Recife: UFPE, 2014.

PONTE, J. P. Formação do professor de Matemática: perspectivas atuais. In: PONTE, J. P. (Org.). Práticas Profissionais dos Professores de Matemática. 1. ed. [S.1: s.n.], 2014. p. 343-360.

ROSA, M.; PAZUCH, V.; VANINI, L. Tecnologias no ensino de Matemática: a concepção de cyberformação como norteadora do processo educacional. In: XI ENCONTRO GAÚCHO DE EDUCAÇÃ̃O MATEMÁTICA, 11., 2012, Lajeado/RS. Anais... Lajeado/RS: [s.n.], 2012. p. 1-7.

SILVA, E. C.; MEDEIROS, D. O.; MORELATTI, M. R. M. Avaliação dos laboratórios de informática das escolas estaduais de presidente prudente no contexto do programa acessa escola. In: I SEMINÁRIO INTERNACIONAL DE OBSERVATÓRIOS DE EDUCAÇÃO E FORMAÇÃO, 1. 2014, Porto.. Anais... Porto - Portugal: [s.n.], 2014.

SOUTO, D. P. L. Transformações expansivas em um curso de Educação Matemática a distância online. 2013. 279 f. Tese (Doutorado em Educação Matemática) - Instituto de Geociências e Ciências Exatas, Universidade Estadual Paulista "Júlio de Mesquita Filho", Rio Claro, 2013.

ZAMPIERI, M. T. Digital technologies and curriculum for teaching Mathematics: Planning a blended continuing education course. In: III CONGRESSO INTERNACIONAL DAS TIC NA EDUCAÇÃO, inserir número do evento, 2014, Lisboa/Portugal. Anais... Lisboa/Portugal: [s.n.], 2014.

ZAMPIERI, M. T.; CHINELlATO, T. G.; CHIARI, A. S. S. As Pesquisas em desenvolvimento no GPIMEM: algumas considerações. In: BORBA, M. C.; CHIARI, A. S. S. (Org.). Tecnologias Digitais e Educação Matemática. 1. ed. São Paulo: Editora Livraria da Física, 2013.

Submetido em Abril de 2015. Aprovado em Julho de 2015. 


\section{ANEXO}

$\underline{\text { Roteiro - Cone e cilindro de revolução }}{ }^{9}$

Objetivo - Que os alunos compreendam dois sólidos de revolução

\section{Cilindro}

1 - Criar um vetor, conforme abaixo:

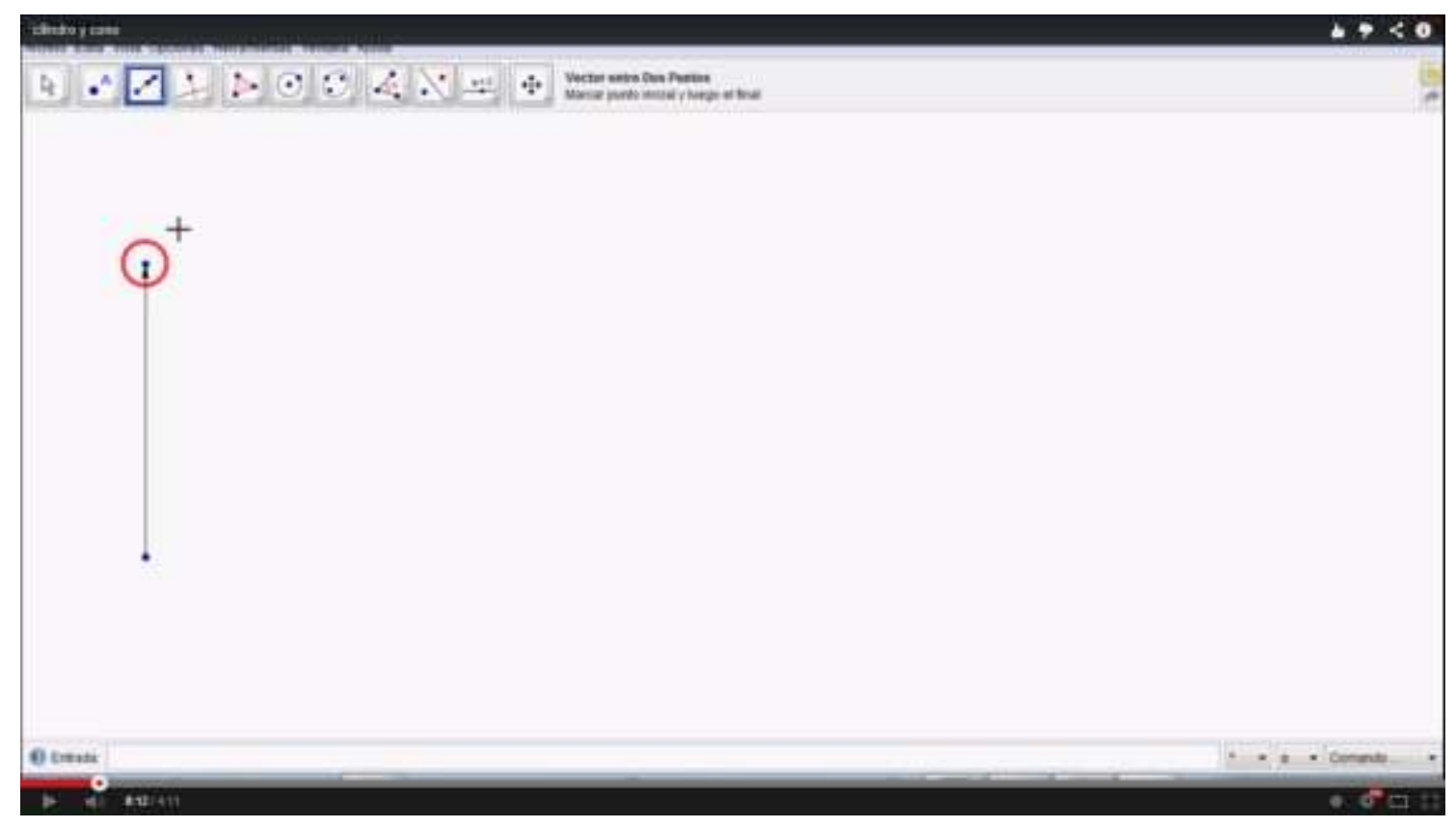

2 - Criar uma elipse, e colocar outro ponto em sua borda, conforme abaixo.

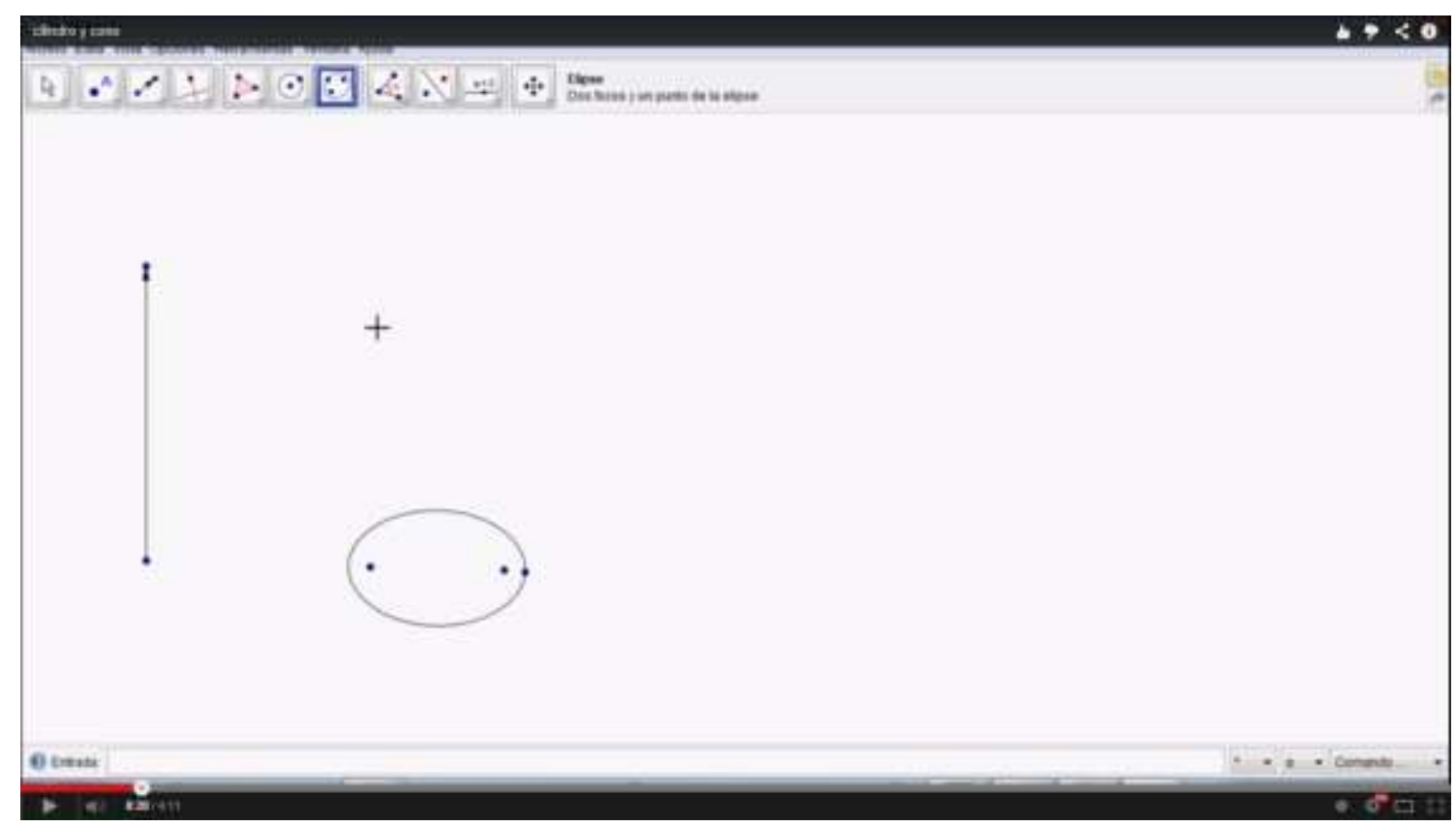

${ }^{9}$ Atividade baseada em http://tube.geogebra.org/student/m50319 . Último acesso em 27.04.2015. 
3 - Achar o ponto médio entre os dois pontos que estão dentro da elipse.

4 - Esconder todos os pontos, exceto o ponto médio.

5 - Na quarta janela da direita para a esquerda, clique em transladar por um vetor, aí clique na elipse e depois no vetor. Deverá ocorrer algo semelhante com a figura abaixo:

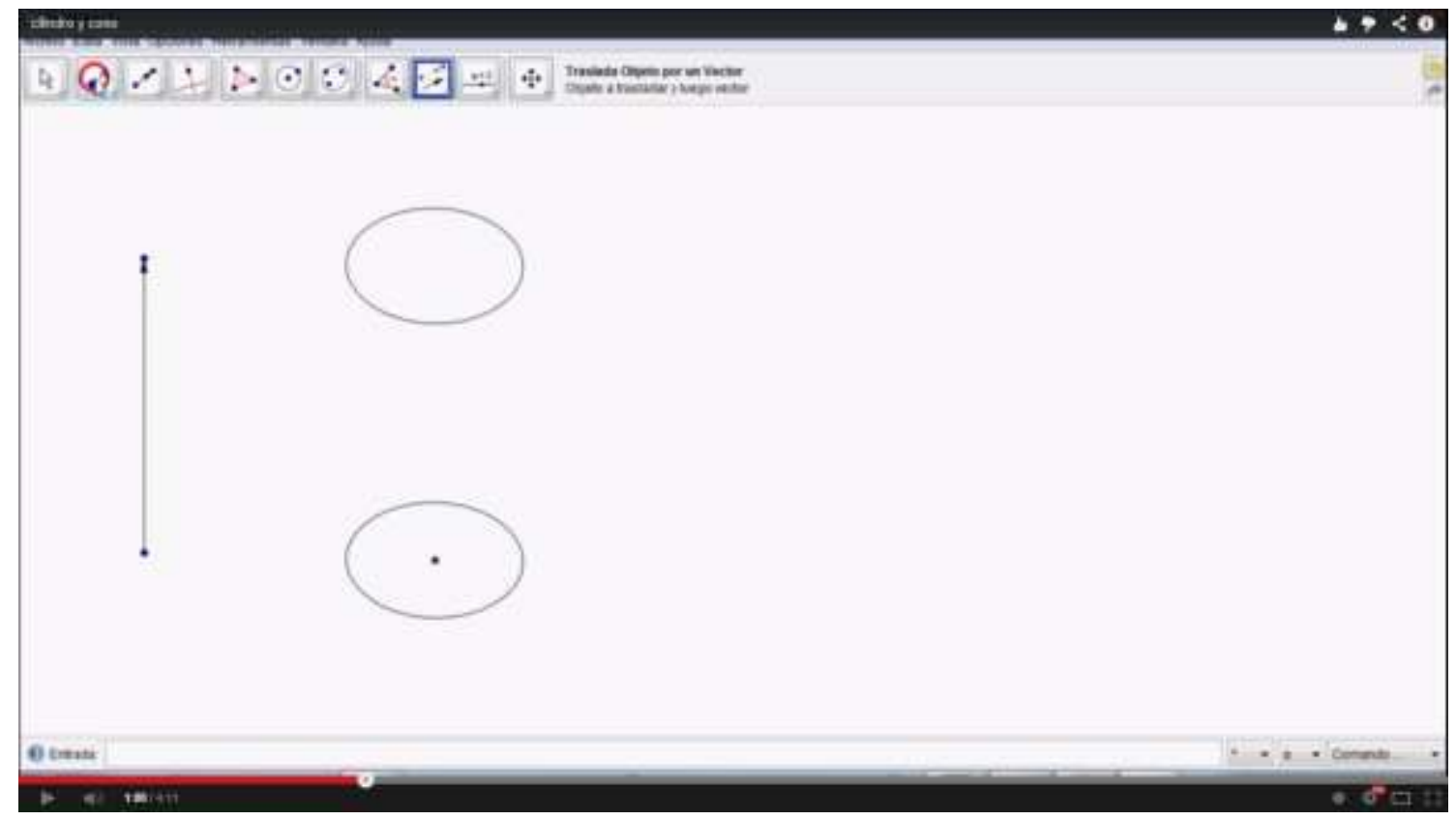

6 - Coloque um ponto sob a elipse, depois clique novamente em transladar por um vetor, aí clique no ponto, e depois no vetor, deverá aparecer um ponto transladado na elipse nova.

7 - Em seguida, clique em segmentos, e ligue o ponto original com o transladado, de modo que tal segmento também esteja alinhado com esse centro, de forma análoga a figura abaixo.

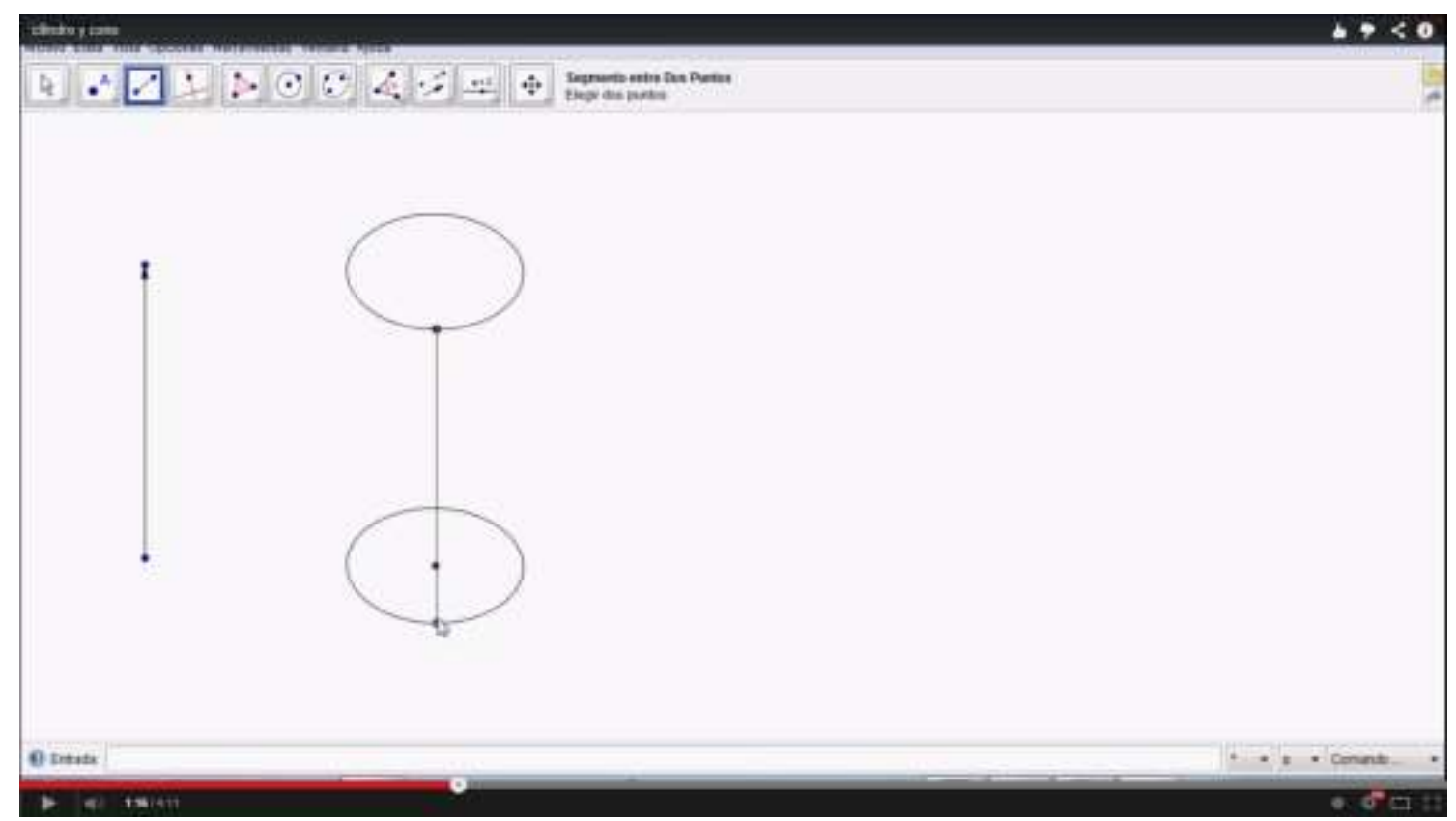


8 - Mude a cor do segmento e habilite seu rastro, aí basta movimentar, conforme abaixo:

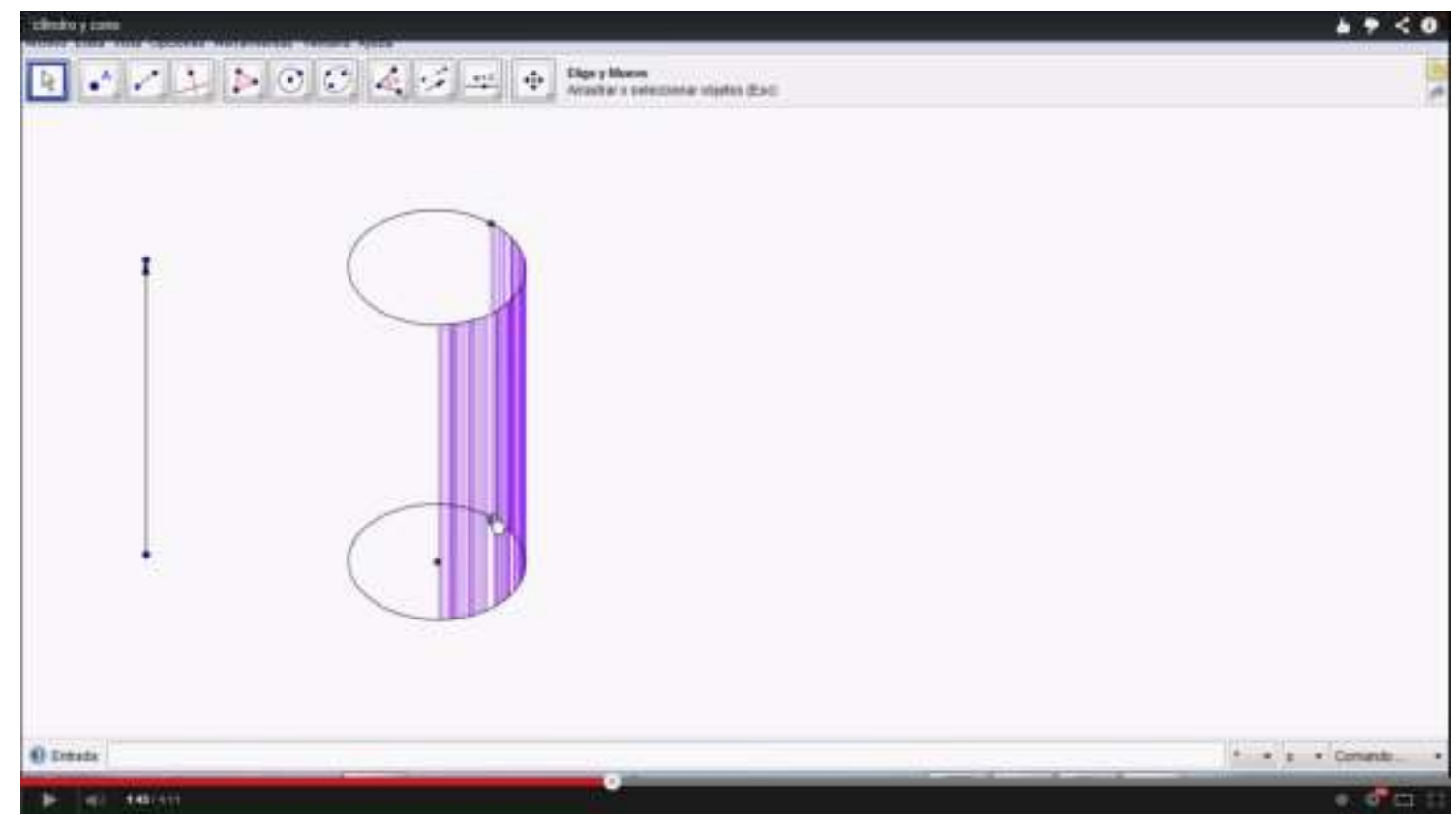

OBS. Uma opção adicional é criar um segmento entre o centro e o ponto da elipse original e transladá-los para a outra elipse, como na figura abaixo:

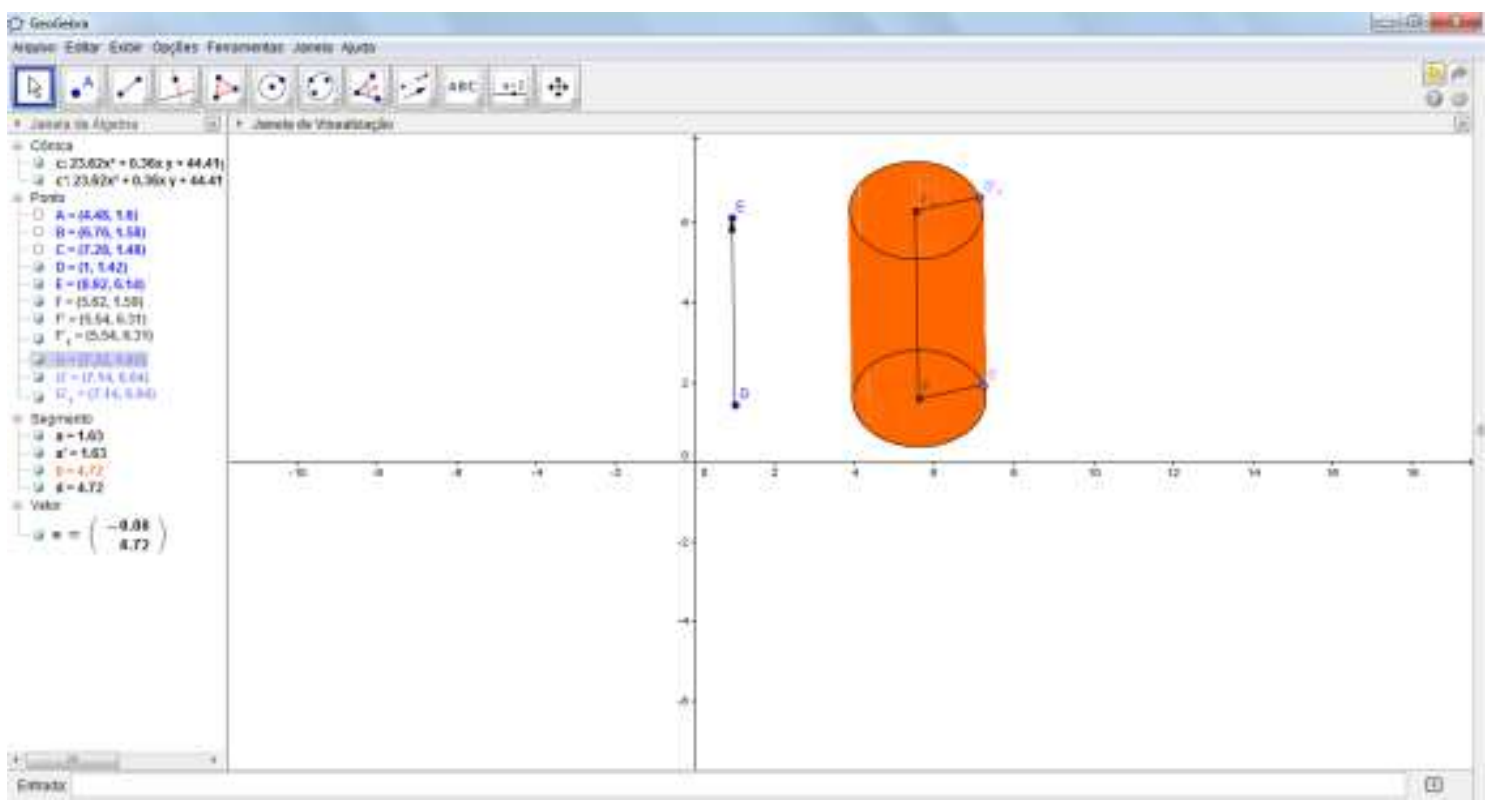

\section{$\underline{\text { Cone }}$}

1 - Crie uma elipse de forma análoga ao que foi feito no cilindro, novamente ache o ponto médio entre os dois pontos. Depois esconda todos os pontos, exceto o centro.

2 - Clique em transladar por um vetor, depois clique no centro e no vetor (o mesmo usado no cilindro), o centro será então transladado.

3 - Depois coloque um ponto sob a elipse, e ligue esse ponto ao centro transladado, da forma como está na figura: 


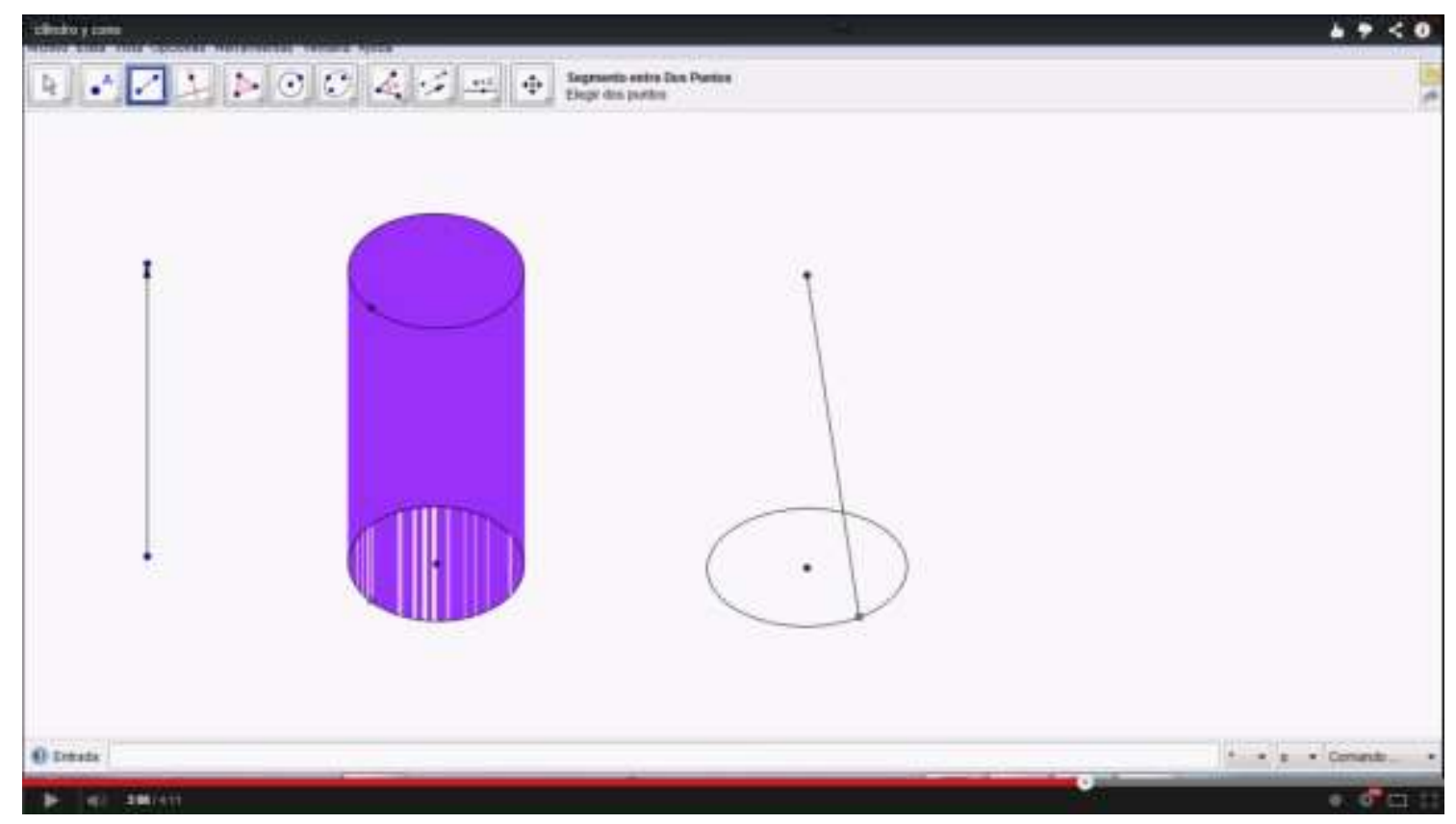

4 - Mude a cor desse segmento, e habilite o rastro, algo semelhante com o que consta abaixo deve ocorrer.

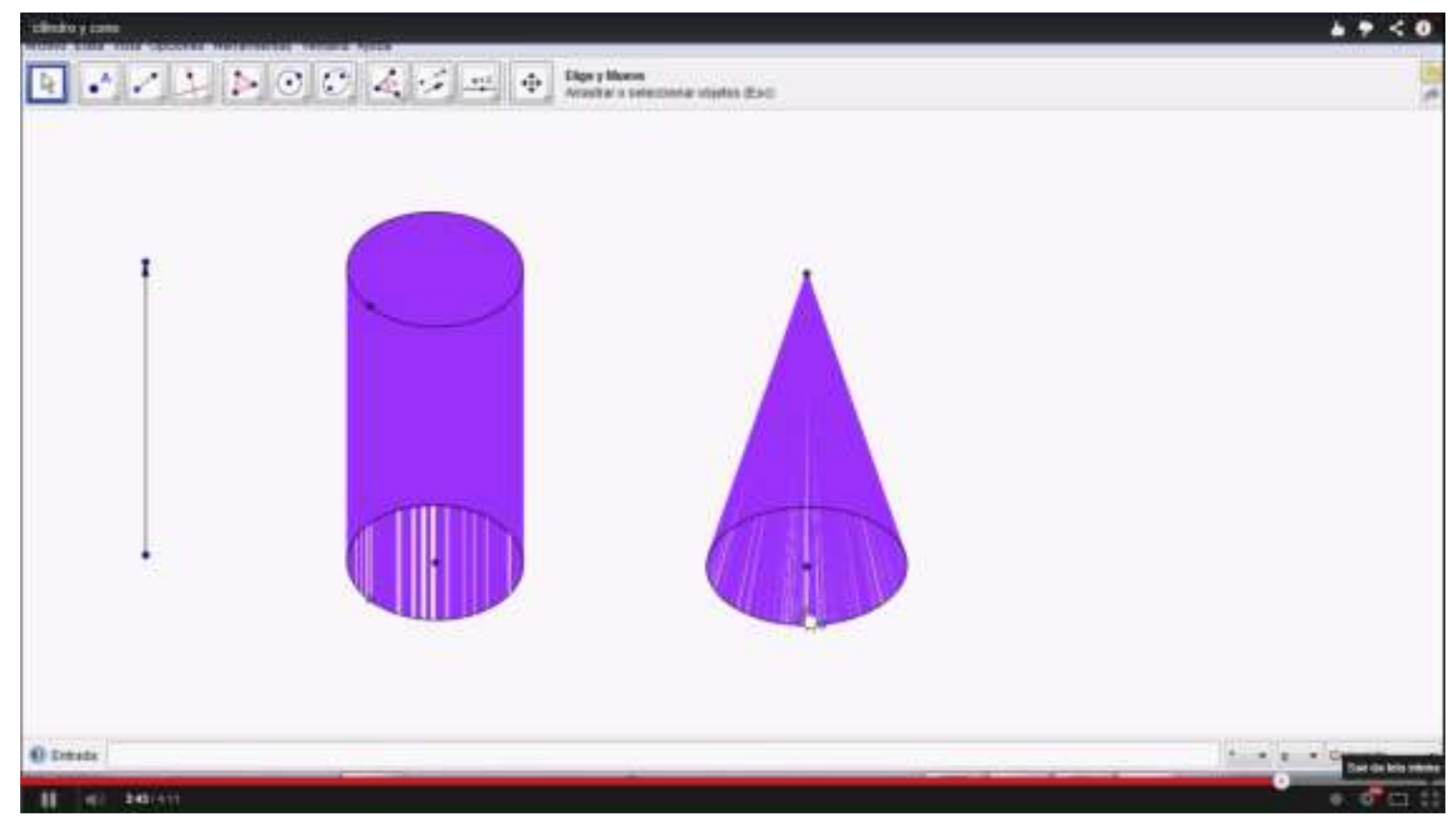

Sugestão de questão para os alunos:

1 - Que figura plana que dá origem ao cilindro quando a movimentamos em torno de um eixo? E qual figura plana dá origem ao cone?

\section{Nosso debate}


1 - Como você avalia essa atividade no GeoGebra em relação ao objetivo que ela visa cumprir? Argumente.

2 - Que adaptações você faria nessa atividade pensando em sua sala de aula?

3 - Quais as potencialidades do GeoGebra nesse tipo de atividade e quais as limitações dele? 